\title{
Glottic foreign bodies in infants: A series of four cases
}

\author{
Aayush Mittal $^{1^{\star}}$, Rahul Bhargava ${ }^{2}$, Sunil Kumar ${ }^{2}$, Jatinder Kumar Sahni ${ }^{2}$ \\ ${ }^{1}$ Department of Otorhinolaryngology-Head \& Neck Surgery, Hind Institute of Medical Sciences \& Shekhar Hospital, Lucknow, India; \\ ${ }^{*}$ Corresponding Author: aayush mittal@yahoo.com \\ ${ }^{2}$ Department of Otorhinolaryngology-Head \& Neck Surgery, Lady Hardinge Medical College, New Delhi, India; \\ dr.rahul.bhargava@gmail.com, suku321@,rediffmail.com, drjksahni@yahoo.co.in
}

Received 9 July 2013; revised 5 August 2013; accepted 12 August 2013

Copyright (C) 2013 Aayush Mittal et al. This is an open access article distributed under the Creative Commons Attribution License, which permits unrestricted use, distribution, and reproduction in any medium, provided the original work is properly cited.

\begin{abstract}
Foreign body in glottis especially in infants is rare. Retrieval of foreign body is a rather simple procedure but sharing of the airway with the anaesthetist and impeding complication makes it more challenging and dangerous. Making a diagnosis of foreign body is most challenging in delayed cases. Complete history and detailed physical examination along with high index of suspicion, in cases of persistent cough, fever, nonresolving respiratory infection, are needed to rule out airway especially laryngeal foreign body. This series of 4 cases is being reported because of the rarity of the glottis foreign body in infants.
\end{abstract}

Keywords: Foreign Body; Bronchoscopy; Infant; Glottis

\section{INTRODUCTION}

Aspiration of foreign bodies in trachea-bronchial tree is common. Most patients are younger than 4 years old [1]. In literature, incidence of foreign body of the larynx has been reported from $0.7 \%$ to $6.1 \%$ among all aero-digestive foreign bodies [2-4]. Delay in diagnosis of the foreign body in airway has the potential to make a difficult situation even more serious [5].

\section{PATIENTS AND METHODS}

We reviewed the data of 79 patients with suspected history of foreign body aspiration who presented to the ENT casualty and pediatric emergency during a period of one year from August 2011 to August 2012.

\section{RESULTS}

In 6/79 (7.59\%) patients foreign bodies were retrieved from glottis, in among these $4 / 6(66.67 \%)$ patients were under the age group of one year. All the four patients presented with the complaint of breathing difficulty of two days to two months duration (Table 1). Two of them had a history of choking and change in voice while two of them had a history of coughing and cyanosis. One of the patients was being treated for upper respiratory tract infection in some peripheral hospital with antibiotics and nebulisation for two months. Another patient was referred from the pediatric department for non-resolving respiratory distress of more than one week, the child had undergone fibreoptic laryngoscopy and was reported to be normal.

On examination all children were having respiratory distress of varying proportion however apparent suprasternal and intercostal retractions with biphasic stridor was present in 2 of the patients. Children were afebrile having no cyanosis. No abnormal cry or palpatory thud was noted over the trachea in any case. On auscultation bilateral air entry was equal in all cases with conducted sound in 2 cases. Rest of ENT examination as well as systemic examination was unremarkable.

Routine haematological and urine examinations were normal. X-ray of antero-posterior and lateral view of soft tissue neck revealed foreign body in the larynx in only three patients (Figure 1). Considering the possibility foreign body these children were subjected to microlaryngoscopy/bronchoscopy under general anesthesia on emergency basis.

During the anesthesia, the children were induced using inhalational sevoflurane only with oral mask. No endotracheal tube was introduced throughout the procedure. Under deep inhalational anesthesia, direct laryngoscopy was done with videolaryngoscope and the foreign body was visualised entrapped in the endolarynx (Figure 2), which were removed using the appropriate forceps. The retrieved foreign bodies included a triangular piece of 
glass, foil of the strip of medicine, a piece of plastic toy, buckle of belt (Figure 3). Check bronchoscopy was done after the foreign body removal which was unremarkable in all except in patient with long standing complaints
(Patient No 1) where raw areas on both cords at middle third were observed. Subsequently, all children were observed for overnight for any complication. Post-operative period was uneventful and children were discharged on

Table 1. Demographic profile of cases of foreign body larynx.

\begin{tabular}{|c|c|c|c|c|}
\hline S. No. & Age/sex & Symptoms & Duration of symptoms & Type of foreign body \\
\hline Patient 1 & $11 \mathrm{~m}$, male & Breathing difficulty, change of voice, choking & 2 months & Triangular glass piece \\
\hline Patient 2 & $8 \mathrm{~m}$, male & Breathing difficulty, change in voice & 2 days & Foil of strip of medicine \\
\hline Patient 3 & $5 \mathrm{~m}$, female & Weak cry, breathing difficulty, cyanosis & 5 days & Piece of plastic toy \\
\hline Patient 4 & $9 \mathrm{~m}$, male & Breathing difficulty, choking, cough & Few hours & Buckle of belt \\
\hline
\end{tabular}

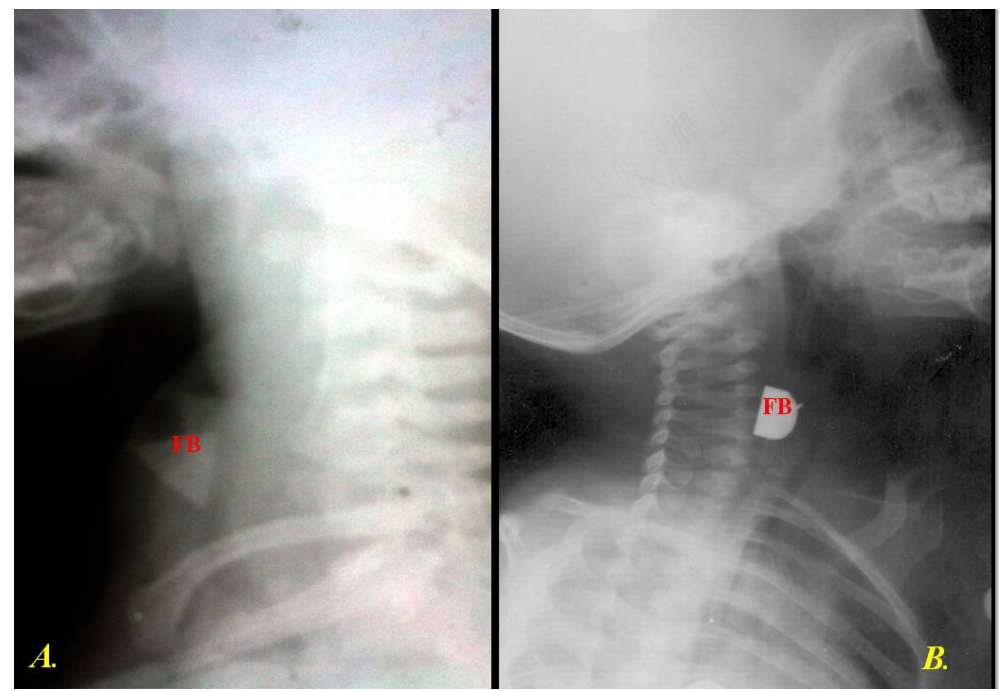

Figure 1. X-Ray Soft tissue neck Lateral view showing the foreign body (FB). (A) Triangular glass piece; (B) Buckle of belt.

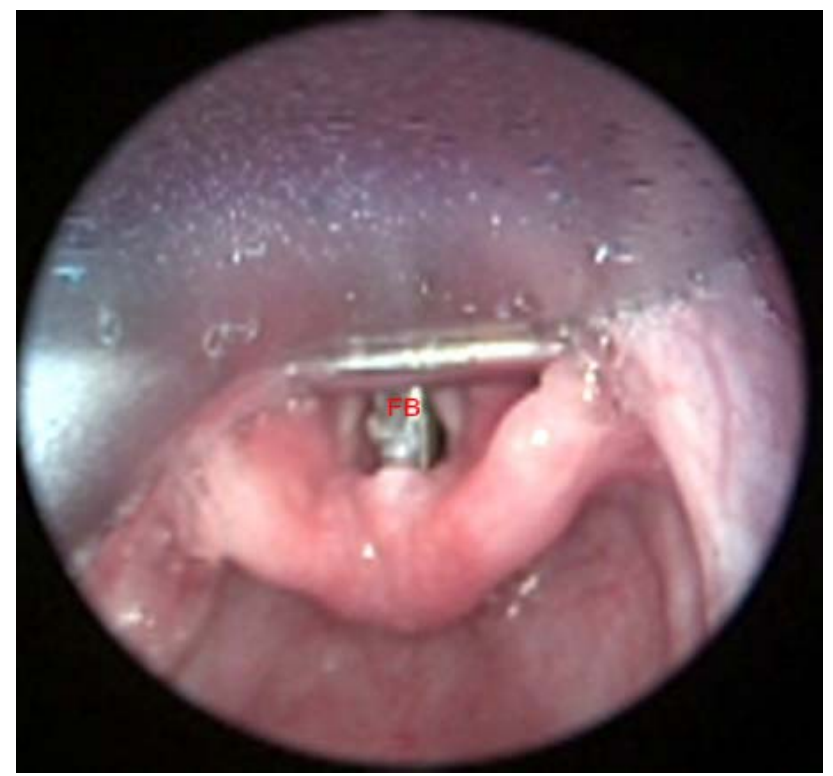

Figure 2. Foreign body (FB) covering the entire glottic chink. 


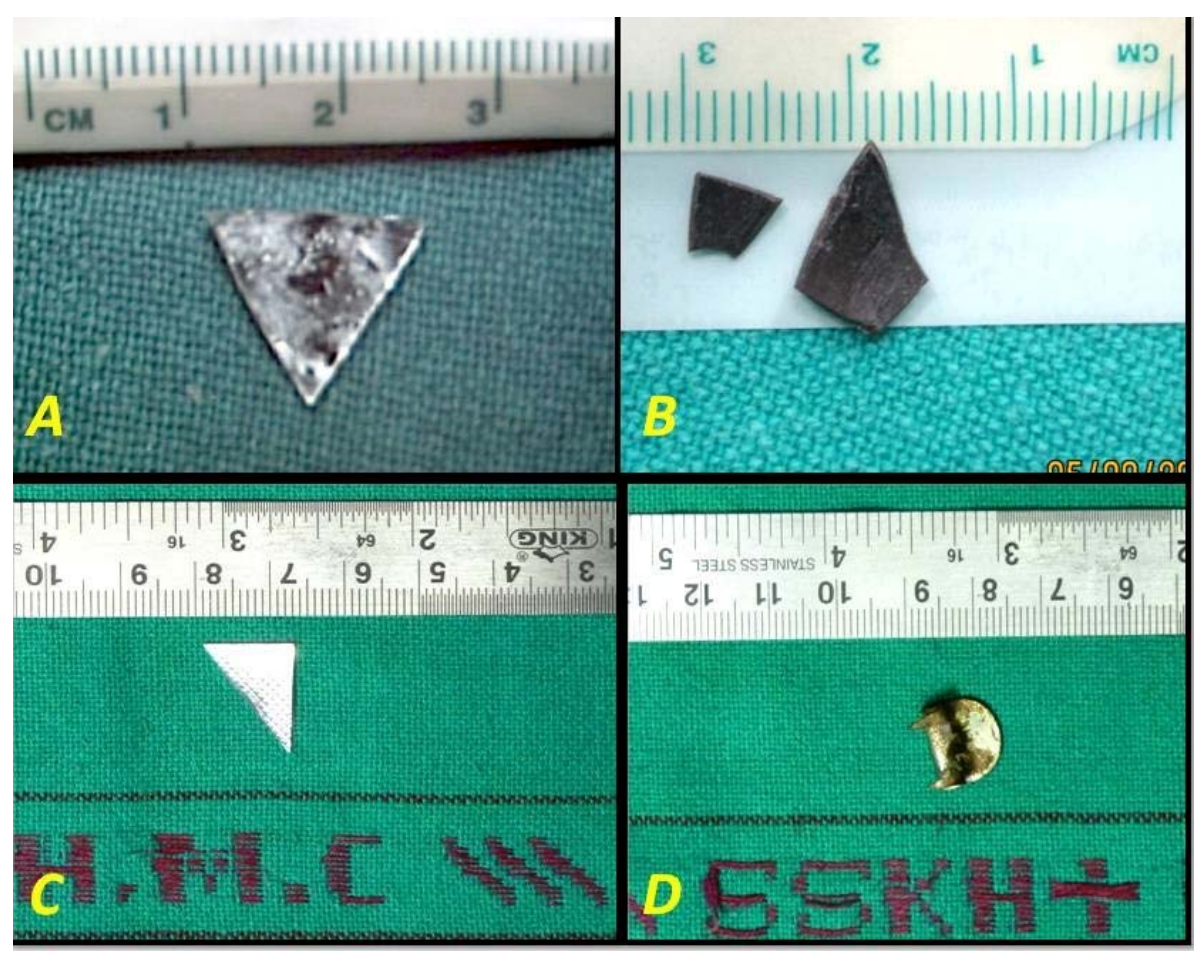

Figure 3. Retrieved foreign bodies. (A) Triangular glass piece; (B) Pieces of plastic toy; (C) Foil of strip of medicine; (D) Buckle of belt.

next day without any medication.

\section{DISCUSSION}

Foreign body larynx is not a common occurrence. Brkić [2], Lemberg [3], and Bittencourt [4] reported its incidence from $0.7 \%$ to $6.1 \%$ amongst all aero-digestive foreign bodies. It is prudent to diagnose aero-digestive foreign bodies as early as possible to minimize potential life-threatening complications in particular glottic foreign body. However, in many cases it is not easy to make the diagnosis as classical symptoms of choking, wheezing, and decreased breath sounds are absent [6]. The delay in diagnosis is attributable to patients' behaviour or circumstances where aspiration was unwitnessed [7]. Once the anaesthesia along with muscle relaxants is given, foreign body might fall down to subglottis or trachea which is a more difficult area to deal with.

The present case series reviews the prevalence of foreign body entrapped in the glottis in children, their presentation and duration of symptoms, and various types of foreign bodies encountered during their retrieval.

Making a diagnosis of foreign body is most challenging in delayed cases [5]. Complete history and detailed physical examination along with high index of suspicion, in cases of persistent cough, fever, non-resolving respiratory infection, are needed to rule out airway especially laryngeal foreign body. It also requires prior discussion and delibuation with anaesthetist due to potential diffi- culty and complication that might occur during the procedure so that everybody in operating room is mentally prepared for the worst.

\section{REFERENCES}

[1] Holinger, L.D. (2007) Foreign bodies of the airway. In: Kliegman, R.M., Behrman, R.E., Jenson, H.B. and Stanton, B.F., Eds., Nelson Textbook of Pediatrics, 18th Edition, Saunders Elsevier, Philadelphia, 1769-1770.

[2] Brkić, F., Delibegović-Dedić, S. and Hajdarović, D. (2001) Bronchoscopic removal of foreign bodies from children in Bosnia and Herzegovina: Experience with 230 patients. International Journal of Pediatric Otorhinolaryngology, 60, 193-196. doi:10.1016/S0165-5876(01)00531-6

[3] Lemberg, P.S., Darrow, D.H. and Holinger, L.D. (1996) Aerodigestive tract foreign bodies in the older children and adolescent. Annals of Otology, Rhinology, and Laryngology, 105, 267-271.

[4] Bittencourt, P.F.S., Camargos, P.A.M., Scheinmann, P. and de Blic, J. (2006) Foreign body aspiration: Clinical, radiological findings and factors associated with its late removal. International Journal of Pediatric Otorhinolaryngology, 70, 879-884. doi:10.1016/j.ijporl.2005.09.024

[5] Franzese, C.B. and Schweinfurth, J.M. (2002) Delayed diagnosis of a pediatric airway foreign body: Case report and review of the literature. Ear, Nose \& Throat Journal, 81, 655-656. 
[6] Reilly, J., Thompson, J., MacArthur, C., Pransky, S., Beste, D., Smith, M., et al. (1997) Pediatric aerodigestive foreign body injuries are complications related to timeliness of diagnosis. Laryngoscope, 107, 17-20.

doi:10.1097/00005537-199701000-00006
[7] Esclamado, R.M. and Richardson, M.A. (1987) Laryngotracheal foreign bodies in children, a comparison with bronchial foreign bodies. American Journal of Diseases of Children, 141, 259-262. 